\title{
A necessidade do impossível: o paradoxo da historiografia literária no Brasil nas primeiras décadas após a independência
}

\author{
The need of the impossible: the paradox of Brazilian Literature \\ in the first decades after the country's independence
}

\author{
Luís ROBERTO DE SOUZA JÚNIOR \\ Pontifícia Universidade Católica do Rio Grande do Sul
}

2

\begin{abstract}
Resumo: A historiografia literária brasileira viveu uma situação paradoxal nas primeiras décadas após a Independência do país (1822). A literatura, na condição de item de um sistema simbólico que ajudava a delinear o conceito de nação, precisava de uma historiografia para legitimá-la. Por outro lado, não era possível cunhar uma historiografia, dado que o Brasil não possuía ainda obras representativas de um sistema literário, conforme os parâmetros estabelecidos por Antonio Candido. O artigo trata desse paradoxo, tomando como base em textos de estudiosos da literatura e historiadores. Também se mostra como essa situação transparece em três textos do período: "Sobre a história da literatura do Brasil" (1836), de Gonçalves de Magalhães; "Bosquejo da história da poesia brasileira" (1840/41), de Joaquim Norberto de Sousa Silva; e "Da nacionalidade da literatura brasileira" (1843), de Santiago Nunes Ribeiro.
\end{abstract}

Palavras chave: Historiografia literária; Literatura brasileira; Sistema literário

\begin{abstract}
Brazilian literary historiography lived a paradoxical situation in the first decades after the country's independence (1822). The literature, as a part of a symbolic system that helped to shape the concept of nation, needed a historiography to legitimize it. On the other hand, it was not possible to coin a historiography, given that Brazil did not yet have enough representative works that would constitute a literary system, according to the definition of Antonio Candido. Based on texts of literature scholars and historians, this article analyses this paradox. It also shows how this situation is seen in three texts of the period: "Sobre a história da literatura do Brasil" (1836), by Gonçalves de Magalhães; "Bosquejo da história da poesia brasileira" (1840/41), by Joaquim Norberto de Sousa Silva; and "Da nacionalidade da literatura brasileira" (1843), by Santiago Nunes Ribeiro.
\end{abstract}

Keywords: Literary historiography; Brazilian literature; Literary system

\section{Introdução}

Siegfried J. Schmidt (1996) escolheu uma questão paradoxal - "Escrever histórias da literatura: um projeto necessário e impossível?" - como subtítulo à primeira seção do ensaio "Sobre a escrita de histórias da literatura: observações de um ponto de vista construtivista", no qual expõe certos dilemas atuais da historiografia literária. Segundo o estudioso, o aspecto mais problemático da escrita de uma história da literatura é a construção de uma rede de relações, conexões e transições, ou como ele especifica, "a concatenação dos dados em unidades coerentes, tais como períodos, épocas, gêneros e assim por diante" (SCHMIDT, 1996, p. 104). O autor avalia que a dificuldade ocorre porque a construção dessas "unidades coerentes" depende de conceitos - como os próprios conceitos de literatura e história - e abordagens variáveis, que são escolhidos pelo historiador: "Em outras palavras: os historiadores literários, em virtude de seu discurso, impõem certas estruturas, ordens, regimes e outras coisas semelhantes aos [...] dados ou testemunhos de acontecimentos históricos" (SCHMIDT, 1996, p. 104).

O teórico alerta que nunca se deve perder de vista o que ele chama de "noção de sistema" e que, aplicado à literatura, define processos e ações literários como processos e ações sociais. "Um sistema literário só pode ser compreendido e explicado no contexto sistemático de (todos) os outros sistemas ativos da sociedade em certo ponto de desenvolvimento sócio-histórico" (SCHMIDT, 1996, p. 113). 
Nessa perspectiva - que inclui a substituição do conceito do que é literatura pelo conceito do que é literário, pois os textos têm valores relativos - marcada pela pluralidade, deve-se falar em histórias (no plural) da literatura, e cada uma delas será fragmentária e aberta e manterá uma relação de interdependência com as outras e com os outros processos da vida social.

"Um projeto necessário e impossível?" - Schmidt formulou a pergunta ao analisar o esforço empreendido a partir da década de 1970 na Alemanha em buscar novas formas de escrever histórias da literatura. A frase, porém, aplica-se perfeitamente à situação da historiografia literária do Brasil em meados do século 19. Nunca em terras brasileiras foi ao mesmo tempo tão necessário e impossível escrever uma história da literatura como o foi nas primeiras décadas após a Independência.

Neste artigo, pretendo explicitar os motivos desse paradoxo, apoiando-me em textos de historiadores Afonso Carlos Marques dos Santos, José Murilo Carvalho - e estudiosos da literatura - Afrânio Coutinho, Antonio Candido e Alfredo Bosi. Mais: intento mostrar como a situação paradoxal transparece em três textos de "grandes espíritos brasileiros" (COUTINHO, 1968, p. 32) atuantes do período: "Sobre a história da literatura do Brasil" (1836), de Gonçalves de Magalhães; "Bosquejo da história da poesia brasileira" (1840/41), de Joaquim Norberto de Sousa Silva; e "Da nacionalidade da literatura brasileira" (1843), de Santiago Nunes Ribeiro ${ }^{1}$.

\section{Da necessidade}

É lícito afirmar que, em 7 de setembro de 1822, quando D. Pedro I proclamou a Independência, tornando-se em seguida o primeiro imperador do Brasil, ele não tinha efetivamente uma nação para governar ${ }^{2}$. Conforme os estudos de José Murilo de Carvalho e Leslie Bethel (2001), em 1822 o Brasil não possuía uma unidade econômica nem um forte senso de identidade nacional. Os historiadores afirmam que a unidade era apenas política e se manteve precária durante todo o primeiro reinado (1822-1831) e período regencial (1831-1840)ํ․ Urgia não

\footnotetext{
1 Tanto Gonçalves de Magalhães quanto Joaquim Norberto de Sousa Silva e Santiago Nunes Ribeiro trabalharam o Instituto Histórico e Geográfico Brasileiro (IHGB). Criado em 1838, tendo recebido o patronato do imperador D. Pedro II, o IHGB também compõe os esforços para legitimar a nação brasileira. Financiava pesquisas e promovia a cultural nacional. O IHGB ainda está na ativa.

2 Uma definição dicionarizada do termo nação aponta como primeiras recorrências "Conjunto de indivíduos habituados aos mesmos usos, costumes e línguas" e "Estado que se governa por leis próprias". <http:// www.priberam.pt/DLPO/nação>.

3 Após a abdicação de d. Pedro I, em 1831, com a qual termina o Primeiro Reinado, foi instituído um governo provisório - o Período Regencial - até que d. Pedro II, herdeiro legítimo do trono, atingisse a maioridade. O governo provisório existiu até 1940 , quando ocorreu a antecipação da maioridade de d. Pedro II, então com 14 anos. O período regencial (1831-1840) foi marcado por lutas políticas, insurreições e guerras civis separatistas.
}

só completar a organização do Estado, mas também, e principalmente, a organização, ou a forja, ou a invenção, do país enquanto nação.

Afonso Carlos Marques dos Santos (1985) opina que tudo estava por construir: símbolos, instituições e o conceito de povo brasileiro. Para o historiador, ao abordar o período é fundamental compreender as construções imaginárias estruturantes da sociedade e identificar os significados simbólicos do processo:

Tratava-se agora de inventar o Brasil, não apenas no plano geopolítico, mas também no plano simbólico, forjando as bases da sua identidade. São neste sentido que devem ser compreendidos os esforços dos letrados brasileiros contemporâneos à formação do Estado Imperial, e a produção artística do período, tanto no campo das letras como das artes plásticas. (SANTOS, 1985, p.4)

Portanto, a literatura se incluía num aparato simbólico que deveria delinear os contornos da nação. A partir disso, enceta-se um movimento voltado à criação de uma literatura nacional e surge a necessidade de uma historiografia para legitimá-la.

Alfredo Bosi (2012) assevera que, dado que o Brasil - a exemplo de outros egressos do sistema colonial - era um país à procura de identidade e autoafirmação, tornavase "imperioso à geração que fizera a independência e aos seus imediatos descendentes identificar a diferença em relação à metrópole que os dominara e os forjara por três séculos" (BOSI, 2012, p. 232).

A primeira versão de "Sobre a história da literatura do Brasil" foi produzida por Gonçalves de Magalhães em 1934 para uma comunicação no Instituto Histórico de Paris ${ }^{4}$. Dois anos depois o texto foi publicado na Niterói: Revista Brasiliense, um periódico fundado na capital pelo grupo liderado por Magalhães e que teve dois números.

Magalhães informa que "o nosso fim não é traçar a biografia cronológica dos autores brasileiros, mas sim a história da literatura do Brasil" (1999, p. 33). Não é propriamente o que ele faz: "Sobre a história da literatura do Brasil" é antes um esboço, como o subtítulo "estudo preliminar" já deixa claro. Ainda assim, trata-se de um "documento precioso e modesto", um "ponto de partida à teoria do Nacionalismo literário" (CANDIDO, 1997, p. 14), válido como exemplo do "grau de consciência

\footnotetext{
4 A comunicação foi sobre o estado da cultura brasileira. Gonçalves de Magalhães tratou de literatura, Araújo Porto-Alegre de belas-artes e Francisco de Sales Torres Homem de Ciência. Deste grupo de jovens brasileiros em Paris, para onde tinham ido para se cultivar, também faziam parte João Manuel Pereira da Silva e Cândido de Azeredo Coutinho. O grupo empreendeu o transporte para o contexto brasileiro dos ideais românticos então em voga na Europa. A liderança cabia a Magalhães, que teve a "intuição decisiva [...] de definir uma literatura nova no Brasil, que fosse no plano da arte o que fora a independência na vida política e social" (CANDIDO, 1997, p. 13).
} 
crítica" e do "esforço de programar as nossas letras" (BOSI, 1994, p.98). Magalhães é forte partidário da tendência antilusitana, que, compreensivelmente, ganhou força logo após a Independência e permeou o pensamento brasileiro durante todo o século 19. O que Magalhães faz em seu ensaio, como salienta Afrânio Coutinho (1968), é interpretar a evolução das Letras nacionais em termos de autonomia. Como podemos notar essas características em "Sobre a história da literatura do Brasil"?

O autor não se cansa de criticar Portugal, que "com este sistema exterminador só curava de atenuar e enfraquecer esta imensa colônia [...] Quem não dirá que ele temia que a mais alto ponto o Brasil se erguesse, e a glória lhe ofuscasse" (MAGALHÃES, 1999, p. 32). A partir disso, faz a seguinte pergunta retórica: "E poderse-á com razão acusar o Brasil de não ter produzido gênios de mais subido quilate? Mas que povo escravizado pode cantar com harmonia, quando o retinido das cadeias, e o ardor das feridas sua existência torturam?" (MAGALHÃES, 1999, p. 33).

Dadas essas circunstâncias, "para um país no qual ainda hoje o trabalho dos literatos parece desmerecê-los", Magalhães (1999, p. 33) argumenta que não são poucos os escritores que existem no Brasil e que "o poeta brasileiro não é guiado pelo interesse, e só o amor mesmo da poesia, e de sua pátria o arrasta".

O autor divide em duas partes a História do Brasil, compreendendo a primeira os séculos 16, 17 e 18; a segunda de 1808 (e aqui devemos lembrar que foi o ano da transferência da corte portuguesa para o Rio de Janeiro) até a época na qual ele escreve. Sobre as origens da literatura brasileira, alude a um provável talento dos índios à música e à poesia e lamenta que os jesuítas não tenham registrado os cânticos indígenas. Reconhece que o Brasil deve a Portugal a sua primeira educação. No entanto, não se pode lisonjear esse fato, pois a educação foi "mesquinha", "que bem parece ter sido dada por mãos avaras e pobres" (MAGALHÃES, 1999, p. 37). No século 19, o escritor apregoa que uma nova face literária se apresenta ao país. "Uma só ideia absorve todos os pensamentos, uma nova ideia até ali desconhecida", escreve ele, e essa a ideia é a da pátria. "Ela domina tudo, tudo se faz por ela ou em seu nome. Independência, liberdade, instituições sociais, reformas, política enfim" (MAGALHÃES, 1999, p. 37).

Reclama do fato de a poesia no Brasil ainda não ter perdido o caráter europeu: "não é uma indígena civilizada, é uma grega, vestida à francesa, e à portuguesa e climatizada no Brasil" (MAGALHÃES, 1999, p. 34). E conclama a uma revolução nas letras. Que os brasileiros não imitem mais os antigos. Que os estudem, mas não se escravizem por suas formulas, pois "só pode um poeta chamar-se grande se ele é original" (MAGALHÃES,
1999, p. 34) e o Brasil, um país rico e imenso, como o autor o classifica, "debaixo do mais céu situado", "este vasto Éden" (MAGALHÃES, 1999, p. 37), não se opõe à poesia, "antes pelas suas disposições físicas muito favoneia o desenvolvimento intelectual" (MAGALHÃES, 1999, p. 39).

O "Bosquejo da História da Poesia Brasileira", de Joaquim Norberto de Sousa e Silva, ganhou publicação pela primeira vez em capítulos no jornal $O$ Despertador, entre meados de 1940 e janeiro de 1941. Com algumas revisões, foi republicado como introdução ao seu livro de poemas Modulações poéticas (1941). Segundo Moreira e Zilberman (1998), em O berço do cânone, o "Bosquejo da História da Poesia Brasileira" abriu a Joaquim Norberto de Sousa Silva as portas do Instituto Histórico e Geográfico ${ }^{6}$.

A tese de Sousa Silva é a de que a literatura brasileira se iniciou com o descobrimento do Brasil e desde sempre mostrou características próprias, características essas que tornam impossível, mesmo com os vínculos políticos e de língua entre Brasil e Portugal, considerar a literatura brasileira como parte da portuguesa. Tal posição aparece inequívoca no primeiro parágrafo do "Bosquejo", quando critica os portugueses ao dizer que o Brasil era uma "colônia avexada pelo cativeiro, onde a instrução era um delito e os livros expressamente proibidos" (SILVA, 1998, p. 100) e argumenta que "ainda não éramos nação [...] e já possuíamos uma literatura, senão legitimamente original, - que raras o são -, ao menos em parte, e que ao presente constitui-nos como nação literária uma das primeiras das duas Américas e a única da meridional" (SILVA, 1998, p. 100-101).

Pode-se considerar também que Sousa Silva, de modo involuntário, evidentemente, alude ao paradoxo de uma história da literatura necessária e impossível ao escrever que "Ainda não éramos nação e já tínhamos historiadores, que memorassem as glórias da pátria, e poetas que celebrassem as vitórias de seus concidadãos, recomendando seus nomes e feitos à posteridade" (SILVA, 1998, p. 100).

\footnotetext{
O título remete ao "Bosquejo da história da poesia e língua portuguesa" (1926), de Almeida Garrett, apesar de defender que os habitantes do Brasil deveriam se inspirar em peculiaridades do território, considera a literatura brasileira como parte da portuguesa, devido à língua em comum. Note-se que Sousa Silva, que critica Garrett, tirou o termo língua do título de seu estudo.

6 Ele construiu carreira no Instituto Histórico Nacional, tendo ocupado vários cargos, inclusive o de presidente. Moreira e Zilberman (1998) classificam como fundamental a contribuição de Sousa e Silva à literatura brasileira do século XIX. Bosi (1994) elogia o cuidado da pesquisa e da documentação das monografias de Sousa e Silva e observa que elas foram norteadas pelo mesmo espírito nacionalista de Gonçalves de Magalhães. Segundo Afrânio Coutinho, "merece registro, sem dúvida, a valiosa contribuição de Norberto à literatura brasileira, seja no domínio da criação [...], seja no de erudição, crítica e história [...] deve ser acentuado sobretudo é a sua contribuição à caracterização da literatura brasileira, sua qualificacão nacional, sua defesa com literatura própria, numa época em que isso não estava ainda admitido, ao contrário era contestado". (COUTINHO, 1968, p. 45)
} 
O estudo tem um caráter historiográfico bem mais marcado do que o de Gonçalves de Magalhães. Há, por exemplo, uma periodização que divide a literatura nacional em seis épocas:

- Primeira: desde o descobrimento até fins do século 17.

- Segunda: do começo até meados do século 18.

- Terceira: de meados até o fim do século 18.

- Quarta: do começo do século 19 até a Independência.

- Quinta: da Independência até a reforma da poesia.

- Sexta: da reforma da poesia até os dias então correntes.

A reforma na poesia tal como a entende Sousa Silva é a consumação do que havia predito Ferdinand Denis ${ }^{7}$ : que o Brasil sentia necessidade de adotar instituições diferentes das que lhe impusera a Europa. Para Sousa Silva (1998, p. 137), e não só para ele ${ }^{8}$, a reforma se deu com Gonçalves de Magalhães e seus versos "arrancados do fundo da alma, inspirados pela saudade, pelo amor da pátria e pela religião cristã" (não por acaso, temas caros ao Romantismo, como veremos adiante) e reunidos em Suspiros Poéticos e Saudades (1936).

O estudo termina com a afirmação de que o porvir é a esperança do Brasil. E esse porvir deve ser construído "com o coração palpitante pelo amor de glória, com a mente repleta dos mais patrióticos pensamentos" (SILVA, 1998, p. 139).

A divisão proposta por Sousa Silva é elogiada por Antonio Candido (1975, p. 299) por ser "a primeira tentativa de distinguir períodos configurados em nosso passado literário", mas ele também a considera mecânica. Para Candido, mais razoável é a periodização formulada por Santiago Nunes Ribeiro em "Da nacionalidade da literatura brasileira" (1943). Voltemo-nos, pois, a esse ensaio, que foi publicado no primeiro número da Minerva Brasiliense - Jornal de Sciencias, Lettras e Artes. Ribeiro - por sinal um brasileiro de coração, mas não de nascimento, pois veio com a família do Chile, quando ainda criança - foi um dos fundadores do jornal, e seu texto, um "excelente e importante ensaio" (COUTINHO, 1968, p. 24), responde a afirmações do General Abreu e Lima e do publicista ${ }^{9}$ português José da Gama e Castro. Em artigos anteriores na imprensa, ambos desfizeram da cultura brasileira. O General Abreu e Lima criticou

\footnotetext{
7 O francês Ferdinand Denis publicou em 1826 Resumo da História Literária do Brasil, no qual defendeu uma literatura brasileira autônoma.

8 Vale aqui registrar a afirmação de Antonio Candido de que é provável que a maior influência individual jamais exercida sobre contemporâneos tenha sido, na literatura brasileira, a de Gonçalves de Magalhães. "A impressão de quem lê artigos e prefácios daquele tempo é que só se ingressava nela como seu visto" (CANDIDO, 1975, p. 48).

9 1. Aquele que escreve sobre assuntos públicos (política, questões sociais).

2. Escritor que escreve sobre política. De acordo com o iDicionário

Aulete: <http://aulete.uol.com.br/publicista $>$.
}

a colonização portuguesa, comparando-a com desfavor à espanhola, mas chegando à conclusão que, por ter vindo da portuguesa, a cultura brasileira é insuficiente e não possui uma literatura própria e original. José da Gama e Castro defendeu que as produções literárias dos brasileiros pertenciam a Portugal, uma vez que eram escritas na língua da pátria de Camões.

O texto de Santiago Nunes Ribeiro é relativamente longo, mas sua tese é simples e explanada com rigor. Pode-se resumi-la: a literatura é a expressão do espírito de um povo, e o espírito de um povo depende de outras coisas que não a língua. Outros fatores como a índole, o caráter, as condições físicas e sociais. Portanto, sendo o Brasil um país tão diferente de Portugal, os brasileiros têm seu caráter nacional, então devem ostentar, e com orgulho, uma literatura própria e nacional, e as produções de autores brasileiros nunca pertenceram às letras lusitanas, mesmo durante a época colonial.

O texto chama a atenção pela lógica, pela clareza, pelo didatismo, o que justifica aqui a reprodução de um trecho longo, mas fulcral:

Não é princípio incontestável que a divisão das literaturas deva ser feita invariavelmente segundo as línguas, em que se acham consignadas. Outra divisão talvez mais filosófica seria a que atendesse ao espírito, que anima, à ideia que preside aos trabalhos intelectuais de um povo, isto é, de um sistema, de um centro, de um foco na vida social. Este princípio literário e artístico é o resultado das influências, do sentimento, das crenças, dos costumes e hábitos peculiares a um certo número de homens, que estão em certas e determinadas relações, e que podem ser muitos diferentes entre alguns povos, embora falem a mesma língua. As condições sociais e o clima do Novo Mundo necessariamente devem modificar as obras nele escritas nesta ou naquela língua da velha Europa. (RIBEIRO, 1843, p. 3)

A periodização elogiada por Candido encontra-se no final do texto, quando o autor comenta que ainda restava fixar e caracterizar as épocas da poesia nacional porque as divisões até então propostas eram atadas aos fatos da história política. Ribeiro entende dever dividir a história literária do Brasil em três períodos. O primeiro abrange os tempos decorridos desde o descobrimento do Brasil até meados do século XVII, quando começa o segundo, que vai até 1830 , quando então se inicia o terceiro período ${ }^{10}$.

\footnotetext{
${ }^{10}$ A primeira época pode ser representada por Manuel Botelhos de Oliveira; nela reina o pensamento da literatura espanhola da decadência. A segunda dificilmente pode achar representante, mas julgamos que Silva Alvarenga é o mais próprio, é o que mais ideias mostra filhas da influência então dominadora. Esta época regida pelo espírito das literaturas do século de Luís XIV, e da Voltaire. Terceira época. O seu representante legítimo e natural é o Sr. Dr. Magalhães. (p. 21)
} 


\section{Da impossibilidade}

Apesar de, pelas razões evidenciadas, haver um empenho nas primeiras décadas após a Independência (1922) de se consumar uma historiografia da literatura brasileira, esse projeto era virtualmente impossível de ser levado a cabo com sucesso. O principal motivo para isso, para a escrita de uma necessária história da literatura nacional estar fadado ao fracasso, é que ainda não havia no Brasil "literatura propriamente dita". Para sustentar tal afirmação, recorremos a Antonio Candido. No sólido e clássico estudo Formação da literatura brasileira, o teórico inicia com uma distinção entre "manifestações literárias" e "literatura propriamente dita".

"Manifestações literárias" seriam produções isoladas, não constituindo "um sistema de obras ligadas por denominadores comuns, que permitem reconhecer as notas dominantes de uma fase" (CANDIDO, 1975, p.23). O teórico explica que esses denominadores comuns são engendrados por elementos internos que concorrem para articular as obras: língua, temas e imagens compartilhados, além de elementos de "natureza social e psíquica”. Candido (1975, p. 23) então propõe o seu hoje mais que conhecido tripé autor-obra-público. Nesta acepção, autor seria "um conjunto de produtores literários mais ou menos conscientes de seu papel" (CANDIDO, 1975, p. 23), público seria "um conjunto de receptores formando os diferentes tipos de público, sem os quais a obra não vive" (CANDIDO, 1975, p. 23). Tampouco podemos esquecer que o tripé não se sustenta sem um mecanismo transmissor "de modo geral, uma linguagem traduzida em estilos" (CANDIDO, 1975, p.23) para fazer articulação entre os componentes.

Segundo Candido (1975, p.24), quando o sistema literário se realiza, ocorre a continuidade literária. "É uma tradição [...] transmissão de algo entre os homens, e o conjunto de elementos transmitidos, formando padrões que se impõem ao pensamento ou ao comportamento, e aos quais somos obrigados a nos referir, para aceitar ou rejeitar", assevera ele, para em seguida pontificar: "Sem esta tradição, não há literatura, como fenômeno de civilização" (CANDIDO, 1975, p. 24).

Por esse ponto de vista, existiram no Brasil, durante a colonização, "manifestações literárias", o que não impede que as obras dessa época sejam valoradas. Porém a "literatura propriamente dita", com obras representativas de um sistema: "Salvo melhor juízo, sempre provável em tais casos, isto ocorre a partir dos meados do século 18, adquirindo plena nitidez na primeira metade do século 19" (CANDIDO, 1975, p. 24).
Ao meu ver, a distinta abordagem citada nos parágrafos anteriores ${ }^{11}$ explica o paradoxo da historiografia literária no Brasil nas primeiras décadas após a Independência. Afinal, numa história da literatura $^{12}$,

as obras não podem aparecer em si, na autonomia que manifestam, quando abstraímos as circunstâncias enumeradas; aparecem, por força da perspectiva escolhida, integrando em dado momento um sistema articulado e, ao influir sobre a elaboração de outras, formando, no tempo, uma tradição (CANDIDO, 1975, p. 24).

Pode-se enxergar tal dificuldade - a de não se poder escrever uma história da literatura sem a ocorrência de "literatura propriamente dita" -, ou ecos dela, nos textos de Gonçalves de Magalhães, Joaquim Norberto de Sousa Silva e Santiago Nunes Ribeiro.

Magalhães (1999, p. 33) pondera que "toda a História, como todo o drama, supõe lugar da cena, atores, paixões, um fato progressivo que se desenvolve, que tem sua razão, como tem uma causa e um fim. Sem estas condições nem há História, nem drama". Lamenta as "espessas trevas" na qual o Brasil viveu durante a colonização, nas quais escritores de gênio só podiam ser como "luzes errantes que o peregrino investigador admira em solitária noite nos desertos do Brasil; sim, eles eram como os pirilampos, que no meio das trevas fosforeiam" (MAGALHÃES, 1999, p. 33).

O autor de "Sobre a história da literatura do Brasil" (1836) ainda expõe suas dificuldades para escrever o ensaio: "Aqueles que alguns lumes de conhecimentos possuem sobre a Literatura Brasileira sabem que mesquinhos e esparsos são os documentos que sobre ela consultar-se podem", atesta Magalhães (1999, p.31). Conta que - e aqui é preciso considerar que na época o autor morava na Europa - em busca de obras de referência sobre autores brasileiros, ou de dos próprios livros dos poetas nacionais, andou em todas as bibliotecas de Paris, de Roma, de Florença, de Pádua e de outras cidades italianas, mas pouco, quase nada, encontrou. E acrescenta sobre a escassez de fontes: "Acresce mais que dos nossos primeiros poetas ignoramos as épocas de seus nascimentos, que tanto apreço damos nós aos grandes homens, que nos tomam,

\footnotetext{
${ }^{11}$ A meu ver, a proposta teórica de Candido se mostra primorosa, pois não é cronológica, mas foca nos momentos que ele considera fundamentais Sob essa perspectiva, para esse artigo, é mais do que relevante ele considerar os meados do século 19 como o principal momento decisivo, e mais do que tudo, um momento de formação.

${ }^{12}$ Candido afirma que as obras não poderiam aparecer no Formação da Literatura Brasileira, um livro, segundo ele, de crítica, mas escrito do ponto de vista histórico.
} 
desses homens cuja herança é hoje nossa única glória" (MAGALHÃES, 1999, p. 33).

Joaquim Norberto de Sousa Silva cita o fato de que Portugal não permitia o estabelecimento de oficinas tipográficas na colônia, o que fez com que as obras de autores brasileiros se perdessem "ao meio das trevas da ignorância; as raras publicadas, em tão pequeno número o foram, que poucas chegaram aos nossos dias" (SILVA, 1998, p. 104). No final da introdução de seu "Bosquejo da história da poesia brasileira" (1840/41), o intelectual também se lastima pela raridade de fontes e justifica que sobre muitas obras não emitirá juízo, "por não ser possível obtê-las, não obstante os grandes esforços por nós feitos" (SILVA, 1998, p. 106).

Santiago Nunes Ribeiro, por sua vez, apesar de conclamar que "a poesia brasileira da época anterior à Independência foi o que devia ser" (RIBEIRO, 1943, p. 6), lamuria-se, no início de "Da nacionalidade da literatura brasileira" (1943), que a "instrução literária" no país seja de pouca monta. "Se porém algum tanto satisfatório é o estado da instrução científica, lamentável nos parece o da instrução literária, ao menos do lado teórico" (RIBEIRO, 1943, p. 1).

\section{Considerações finais}

Minha intenção neste artigo foi tomar uma questão paradoxal - "Escrever histórias da literatura: um projeto necessário e impossível?" - enunciada por Siegfried J. Schmidt (1996) e aplicá-la à situação da historiografia literária do Brasil em meados do século 19, período no qual o país se construía como uma nação. A literatura, na condição de item de um sistema simbólico que ajudava a delinear o conceito de nação brasileira, precisava de uma historiografia para legitimá-la. Com efeito - como se evidencia nos textos "Sobre a história da literatura do Brasil" (1836), de Gonçalves de Magalhães; "Bosquejo da história da poesia brasileira" (1840/41), de Joaquim Norberto de Sousa Silva; e "Da nacionalidade da literatura brasileira" (1943), de Santiago Nunes Ribeiro - "a literatura foi considerada parcela dum esforço construtivo mais amplo, denotando o intuito de contribuir para a grandeza da nação" (CANDIDO, 1975, p. 12). Essa tendência historiográfica procurou "valorizar a civilização brasileira, construída pelos 'brasileiros' [...] diferenciando-se logo da metrópole à custa de uma nova experiência histórica, os novos contatos sociais, numa situação geográfica diferente" (COUTINHO, 1968, p. xxii).

Ao mesmo tempo, por outro lado, não era possível cunhar uma historiografia nacional, dado que o país não possuía, até aquele momento, "literatura propriamente dita", com obras representativas de um sistema, conforme os parâmetros estabelecidos por Antonio Candido e adotados nesse artigo. O que resta dizer é que em meados do século 19, quando o sistema literário brasileiro finalmente ganhou corpo, essa configuração se deu com intensa imbricação com o sistema político, o que remete à concepção de SCHMIDT (1996) - com a qual certamente Candido estaria de acordo - de que um sistema literário só pode ser compreendido e explicado no contexto de outros sistemas da sociedade.

Também falta aclarar que, naquele contexto de um país em busca de autoafirmação, a ideologia do Romantismo (e lembremos que Gonçalves Magalhães, em 1936, com Suspiros Poéticos e Saudades foi o catalisador do movimento no Brasil), tendo o nacionalismo como um de seus pilares, além do repúdio aos padrões clássicos (por ventura o padrão da literatura portuguesa durante a época colonial), encaixou-se perfeitamente à necessidade de independência das Letras brasileiras. Por isso - e esse fato também representa o paradoxo cujo este artigo buscou explicitar-, as manifestações críticas e poéticas no Brasil de meados do século 19 seguiram paralelas. Afrânio Coutinho (1968) assevera mesmo que no Romantismo a crítica não sucedeu, mas antecipou-se aos criadores. De certo modo, a historiografia, ou a tentativa dela, da literatura brasileira também o fez.

\section{Referência}

BOSI, Alfredo. História concisa da literatura brasileira. São Paulo: Cultrix, 1984.

CANDIDO, Antonio. Formação da literatura brasileira: momentos decisivos. Belo Horizonte: Itatiaia, 1975. v. 1.

Formação da literatura brasileira: momentos decisivos. Belo Horizonte: Itatiaia, 1975. v. 2.

CARVALHO, J. M; BETHELL, Leslie. O Brasil da Independência a meados do século XIX. In: BETHELL, Leslie (Org.). História da América Latina/Da Independência a 1870. São Paulo: Edusp, 2001. v. III, p. 695-769.

CARVALHO, José Murilo (Org.). A construção nacional (1830-1889). Rio de Janeiro: Objetiva, 2012.

COUTINHO, Afrânio. A tradição afortunada: o espírito de nacionalidade na crítica brasileira. São Paulo: José Olympio, 1968.

DENIS, Ferdinand. Resumo da história da literária no Brasil. Porto Alegre: Lima 1968.

MAGALHÃES, Domingos José Gonçalves de. "Ensaio sobre a história da literatura do Brasil". Cadernos do Centro de Pesquisas Literárias da PUCRS, Porto Alegre, v. 5, n. 2, ago. 1999.

RIBEIRO, Santigo Nunes. "Da nacionalidade da literatura brasileira". Minerva Brasiliense, Jornal de Ciências, Letras e Artes, v. 1, n. 1, nov. 1843

SANTOS, Afonso Carlos Marques dos. "A invenção do Brasil: um problema nacional?”. Revista de História, São Paulo, v. 118 , p. 3-12, jan./jun. 1985. 
SANTOS, Afonso Carlos Marques dos. Nação e História: Jules Michelet e paradigma nacional na historiografia do século XIX. Revista de História, São Paulo, n. 144, p. 153-154, 2001.

SCHMIDT, Siegfried J. Sobre a escrita de histórias da literatura. Observações de um ponto de vista construtivista. In: OLINTO, Heidrun Kreger. Histórias de literatura. As novas teorias alemãs. São Paulo: Ática, 1996. p. 101-131.
SILVA, Joaquim Norberto de Sousa. Bosquejo da história da poesia brasileira. In: MOREIRA, Maria Eunice; ZILBERMAN, Regina. O berço do cânone. Porto Alegre: Mercado Aberto, 1998. p. 89-142.

Recebido: 19 de agosto de 2017 Aprovado: 31 de outubro de 2017 Contato: luis.souza.002@acad.pucrs.br (Luís Roberto de Souza Júnior) 